\title{
RECURSOS DIDÁTICOS UTILIZADOS POR PROFESSORES DE ESCOLAS RURAIS DE UM MUNICÍPIO MATO-GROSSENSE NAS DÉCADAS DE 1980 E 1990
}

\author{
GARCIA, Luana Santos Nogueira ${ }^{1 *}$; MACHADO, IIma Ferreira ${ }^{1 * *}$ \\ ${ }^{1}$ Universidade do Estado de Mato Grosso \\ luaninhanogueira84@gmail.com* \\ ilma.ferreiramachado@gmail.com**
}

\section{RESUMO}

Este texto aborda sobre recursos, equipamentos e materiais didáticos utilizados por professores das escolas do campo no estado de Mato Grosso, especialmente na região de Tangará da Serra, nas décadas de 1980 e 1990. Objetiva caracterizar a forma de organização do trabalho pedagógico nas escolas do campo, identificar os tipos de materiais e recursos didáticos empregados no desenvolvimento do processo de ensino-aprendizagem e expor as principais dificuldades encontradas pelos professores na realização do trabalho docente. Adotou-se

uma abordagem de pesquisa qualitativa, recorrendo-se à técnica da entrevista semiestruturada. Os resultados apontam que os professores dessas escolas rurais eram, em sua maioria, leigos e atuavam em salas multisseriadas, com uma precária infraestrutura e com pouquíssimos recursos didáticos. Além das orientações periódicas que recebiam da Secretaria Municipal da Educação, os professores buscavam auxílio de colegas docentes da cidade, até mesmo em termos de reaproveitamento de materiais didáticos.

PALAVRAS-CHAVE: Educação do campo. Recursos e materiais didáticos. Organização do trabalho pedagógico.

\section{TEACHING RESOURCES USED BY TEACHERS FROM RURAL SCHOOLS OF A MUNICIPALITY MATO-GROSSENSE IN THE DECADES OF 1980 AND 1990}

\begin{abstract}
This paper approaches about didactic resources and materials skills used by teachers at rural schools in Mato Grosso state, mainly around Tangará da Serra, during the 1980s and 1990s. It aims at characterizing how the pedagogic work is organized at rural schools and the sort of didactic materials and resources used in the teachinglearning process and present the main difficulties faced by the teachers in their teaching work. Qualitative even for reutilization of didactic materials.

KEYWORDS: Rural education. Didactic resources and materials. Organization of pedagogic work.

\section{RECURSOS DIDÁCTICOS UTILIZADOS POR PROFESORES DE ESCUELAS RURALES DE UN MUNICIPIO DE MATO GROSSO EN LAS DÉCADAS DE 1980 Y 1990}

research was used by the semi-structured interview technique. The outcomes of this research show that the teachers from rural schools were mostly lay and worked in mixed grades classes with a meager infrastructure and a shortage of didactic resources. Besides the guidance received from the Municipal Secretariat of Education, the teachers also sought help other teachers in the city

\section{RESUMEN}

Este texto trata sobre recursos, equipos y materiales didácticos utilizados por profesores de las escuelas del campo en el estado de Mato Grosso, especialmente en la región de Tangará da Serra, en las décadas de 1980 y 1990. Objetiva caracterizar la forma de organización del trabajo pedagógico en las escuelas del campo, identificar los tipos de materiales y recursos didácticos utilizados en el desarrollo del proceso de enseñanza-aprendizaje y exponer las principales dificultades encontradas por los profesores en la realización del trabajo docente. Se adoptó un enfoque de investigación cualitativa, empleando la técnica de la entrevista semiestructurada. Los resultados apuntan que los profesores de esas escuelas rurales eran, en su mayoría, laicos y actuaban en clases múltiples, con una precaria infraestructura y con escasos recursos didácticos. Además de las orientaciones periódicas que recibían de la Secretaría Municipal de Educación, los profesores buscaban ayuda de colegas docentes de la ciudad, incluso en términos de reaprovechamiento de materiales didácticos.

PALABRAS CLAVE: Educación del campo. Recursos y materiales didácticos. Organización del trabajo pedagógico. 


\section{INTRODUÇÃO}

A visibilidade que a educação do campo começa a adquirir a partir da aprovação da Resolução no 1/2002, do Conselho Nacional de Educação, tem suscitado um interesse maior pela história dessa modalidade educacional, assim como pela análise de experiências significativas, que, por falta de registro mais sistemático, acabaram ficando apenas na memória dos sujeitos que as vivenciaram. Este estudo insere-se nessa perspectiva, por entendermos ser imprescindível conhecermos nosso passado para compreendermos melhor o presente, assim como para projetarmos o futuro com mais clareza, de modo particular em relação à educação do campo e ao trabalho pedagógico realizado em escolas do campo.

Neste trabalho, trazemos uma discussão sobre os recursos e materiais didáticos utilizados pelos docentes das escolas do campo, especialmente na região de Tangará da Serra, Mato Grosso, nas décadas de 1980 e 1990. O objetivo deste estudo é caracterizar a forma de organização do trabalho pedagógico nas escolas do campo e os tipos de materiais, equipamentos e recursos didáticos empregados pelos professores no desenvolvimento do processo de ensino-aprendizagem; identificar as principais técnicas e estratégias de ensino usadas; e, por fim, expor as principais dificuldades encontradas por professores na realização do trabalho docente.

Este estudo foi realizado por meio de uma abordagem de pesquisa qualitativa, que, segundo Lüdke e André (1986, p. 13), “[...] envolve a obtenção de dados descritivos, obtidos no contato direto do pesquisador com a situação estudada, enfatiza mais o processo do que o produto e se preocupa em retratar a perspectiva dos participantes". Nosso referencial teórico sustenta-se em autores como: Hage (2006), Lüdke e André (1986), Machado (2009), Pinheiro (2007), Ribeiro (2013), Rocha (2010), Souza (2006), Tardif (2002) e Zabatiero (2009). Como instrumentos de coleta de dados, recorremos à entrevista semiestruturada, realizada com quatro professores que atuaram na região de Tangará da Serra nas décadas de 1980 e 1990, os quais se interessaram e se dispuseram a participar.

A partir das entrevistas com esses quatro educadores de escolas do campo - escolas rurais, à época -, fizemos a análise dos dados obtidos, sistematizando os aspectos comuns e também os distintos na realização do trabalho pedagógico desses docentes. As falas dos sujeitos

Educação \& Formação, Fortaleza, v. 2, n. 6, p. 139-152, set./dez. 2017

DOI: http://dx.doi.org/10.25053/edufor.v2i6.2064

http://seer.uece.br/redufor 
constituíram-se em importante instrumento de compreensão de uma parte da história da educação do campo no estado de Mato Grosso.

\section{EDUCAÇÃO RURAL? EDUCAÇÃO DO CAMPO?}

Conforme dados do Ministério da Educação (MEC), metade das escolas do Brasil estão situadas na esfera rural (BRASIL, 2008). Observando a trajetória das escolas rurais, nota-se que durante décadas coube às iniciativas das comunidades a construção e manutenção de escolas nas áreas rurais, grande parte delas funcionando precariamente em espaços físicos inadequados e improvisados, com docentes sem qualificação devida.

[...] a educação do campo tem se caracterizado como um espaço de precariedade por descasos, especialmente pela ausência de políticas públicas para as populações que lá residem. Essa situação tem repercutido nesta realidade social, na ausência de estradas apropriadas para escoamento da produção; na falta de atendimento adequado à saúde; na falta de assistência técnica; no não acesso à educação básica e superior de qualidade, entre outros. (PINHEIRO, 2011, p. 1).

Em 1961, a Lei de Diretrizes e Bases da Educação Nacional (LDBEN), em seu artigo 105, estabeleceu que os poderes públicos apoiassem entidades que mantivessem na zona rural "[...] escolas capazes de favorecer a adaptação do homem ao meio e o estímulo de vocações profissionais". Mesmo com essa lei, a educação rural acabou ficando restrita aos próprios meios e o ensino fundamental foi deixado a cargo dos próprios municípios.

A educação rural, de um modo geral, caracterizou-se pela ausência de investimentos estatais suficientes, de autonomia e de participação dos sujeitos das áreas rurais na definição da proposta educativa e organização das escolas, cabendo aos donos de fazendas a cessão do espaço para que os professores pudessem lecionar, locais estes onde, de modo assistencial, instalou-se grande parte das escolas. Nesse contexto, coube às instituições escolares "repassar" um saber escolar espelhado no currículo urbano, sem atentar-se para a realidade local e para a perspectiva de seus sujeitos.

Em 2002, houve uma modificação na esfera legal e no plano conceitual: as escolas rurais passaram a ser denominadas de escolas do campo, a partir de uma proposição do Movimento Camponês, "[...] unidade que reúne uma diversidade de movimentos sociais populares de luta 
pela terra, em particular, pela reforma agrária, incluindo nessa luta a educação do campo" (RIBEIRO, 2013, p. 672). Com essa conquista, começaram a proliferar as escolas do campo, cujo marco legal foi a Resolução CNE/CEB no 1/2002, que estabelece as diretrizes nacionais para a educação básica no campo. De acordo com essa resolução, a educação do campo caracteriza-se pela identificação com os sujeitos do campo e pela vinculação:

[...] às questões inerentes à sua realidade, ancorando-se na temporalidade e saberes próprios dos estudantes, na memória coletiva que sinaliza futuros, na rede de ciência e tecnologia disponível na sociedade e nos movimentos sociais em defesa de projetos que associem as soluções exigidas por essas questões à qualidade social da vida coletiva no país. (BRASIL, 2002, p. 1).

Demarcar a diferença entre educação rural e educação do campo é importante para situarmos o escopo da análise ora proposta, cujo foco é a educação rural.

\section{TRABALHO PEDAGÓGICO NAS ESCOLAS RURAIS EM UM MUNICÍPIO MATOGROSSENSE}

O município de Tangará da Serra, criado em 1976, situa-se no Sudoeste mato-grossense, a 240 quilômetros de Cuiabá, capital do estado, tendo hoje, de acordo com dados do Instituto Brasileiro de Geografia e Estatística (IBGE), uma população de 96.932 habitantes (IBGE, 2016). Isso significa que, no período considerado para análise desta pesquisa, ou seja, décadas de 1980 e 1990, Tangará era um município extremamente novo. Conforme registros constantes no site do IBGE e confirmado nas falas de alguns entrevistados, a história econômica dessa cidade esteve, nos anos 1980 e 1990, ligada à plantação do café, diversificando-se posteriormente para a agricultura, pecuária, indústria e prestação de serviços. No plano social e político, destaca-se nesse período a heterogeneidade da população, composta por migrantes de São Paulo, Minas Gerais, Paraná, Rio Grande do Sul, bem como por migrantes oriundos de estados nordestinos.

$\mathrm{Na}$ análise da educação rural nesse município, estamos considerando, portanto, o contexto socioeconômico à época, caracterizado pela dinâmica expansionista e de acelerado processo de desenvolvimento urbano, que, de uma forma ou de outra, vai repercutir na dinâmica da educação e da cultura.

Com os dados obtidos nesta pesquisa, é possível notar semelhanças em relação à forma como esses professores entrevistados desenvolviam o trabalho pedagógico à época nas escolas

Educação \& Formação, Fortaleza, v. 2, n. 6, p. 139-152, set./dez. 2017

DOI: http://dx.doi.org/10.25053/edufor.v2i6.2064

http://seer.uece.br/redufor 
rurais, principalmente no final da década de 1980 e início da década de 1990 . Segundo eles, a Secretaria Municipal da Educação (SME) estava sempre preocupada em orientá-los, pois a maioria era leiga ${ }^{1}$ e necessitava de orientação sobre o que e como ensinar. Porém, como era grande a dificuldade de acesso, membros da SME geralmente iam uma vez ao mês visitar as escolas; em outras situações, iam quinzenalmente, conforme afirmou a professora L. F.: “Eles iam, no mínimo, a cada 15 dias mais ou menos, às vezes até uma vez por semana ia uma coordenadora visitar as escolas. O muito que eles passavam eram 20 dias, mas todo mês a gente tinha visita umas duas vezes por mês". A professora Y. C. assim se posicionou: "A secretaria fazia visitas mensais; nessas visitas, eles davam as orientações; cada final de mês, quando a gente vinha para a cidade receber pagamento, também tinha o momento de orientação para os professores".

Assim, em alguns casos, os assessores da SME levavam materiais didáticos necessários à realização do trabalho docente. Conforme relatou a professora Y. C.: "Então, a gente tinha esse acompanhamento da equipe que levava daí outros materiais. Não havia grandes materiais na escola, então eles [membros da SME] levavam daqui o suporte da revista, do livro didático, aquilo que achavam necessário para o trabalho".

Os materiais vinham de forma insuficiente; segundo uma das docentes, elas tinham que "se virar" para dar aulas e elaborar seu trabalho pedagógico. Então, mesmo com toda essa problemática da falta de materiais didáticos, os professores davam algum jeito para realizarem seu trabalho pedagógico. Como em algumas escolas rurais era difícil o recebimento de materiais didáticos, os docentes saíam à procura de materiais usados por outros professores para reutilizá-los em seu ambiente de ensino ou então utilizavam recorte de material que alguma outra escola e/ou professor ofereciam para montarem fichinhas e fazerem atividades para seus alunos. Essa foi a realidade de vários educadores que atuavam nas escolas rurais nas décadas de 1980 e 1990 no estado de Mato Grosso.

Percebe-se pouca diferença entre os entrevistados em relação aos recursos e materiais didáticos utilizados no ambiente escolar (ver Quadro 1). O professor J. B. utilizava cartilhas e estudo do meio; a professora L. F. recorria à pesquisa como estratégia de aprendizagem e também fazia observações no caderno de campo; a professora Y. C. usava revistas, suporte de

1 Expressão que designa os que trabalham nos anos iniciais do ensino fundamental e não têm a formação completa e apropriada para o exercício do magistério.

Educação \& Formação, Fortaleza, v. 2, n. 6, p. 139-152, set./dez. 2017

DOI: http://dx.doi.org/10.25053/edufor.v2i6.2064

http://seer.uece.br/redufor 
livros didáticos, recortes, cópias de textos, estêncil, mimeógrafo a álcool, giz, caderno e também o espaço da própria escola para realizar o estudo do meio denominado "laboratório vivencial". E, por fim, a professora C. A. também fazia estudo do meio empregando os próprios recursos naturais que existiam no entorno da escola; usava lousa e giz, mimeógrafo, sulfite, cartolina, papel pardo e livros didáticos que chegavam à escola de forma escassa.

Quadro 1 - Materiais/recursos didáticos utilizados pelos professores das escolas rurais - Tangará da Serra - 1980 a 1990

\begin{tabular}{|c|c|c|}
\hline Nome & Ano inicial de atuação & Materiais/Recursos didáticos \\
\hline Professor J. B. (Entrevistado 1) & 1983 & Cartilhas, espaço e estudo do meio. \\
\hline Professora L. F. (Entrevistada 2) & 1989 & $\begin{array}{c}\text { Pesquisas e observações com caderno de campo, } \\
\text { cartazes. }\end{array}$ \\
\hline Professora Y. C. (Entrevistada 3) & 1989 & $\begin{array}{c}\text { Revistas, suporte de livros didáticos, recorte material, } \\
\text { coletânea de textos, estêncil, mimeógrafo a álcool, giz, } \\
\text { caderno, espaço e estudo do meio. }\end{array}$ \\
\hline Professora C. A. (Entrevistada 4) & 1990 & $\begin{array}{c}\text { Giz, lousa, mimeógrafo, sulfite, cartolina, papel pardo e } \\
\text { livros didáticos (de forma escassa). }\end{array}$ \\
\hline
\end{tabular}

Fonte: Elaboração própria (2014).

Em termos de infraestrutura, organização e funcionamento das escolas, podemos dizer que predominava certa improvisação de espaços e equipamentos, pois as escolas funcionavam em uma sala ou barracão cedido geralmente pelo proprietário de alguma fazenda, não havendo um quadro de funcionários para executar tarefas da secretaria, limpeza ou merenda. Segundo o professor J. B.:

A professora ou o professor cozinhava junto com os alunos, e, de certa forma, havia até um pouquinho de formação a respeito de economia doméstica, ou seja: 'Olha, gente, nessa época do ano não tem certo produto, isso fica muito caro, então vamos cozinhar 'aquilo', e assim por diante, né?'. E os cuidados que a pessoa deveria ter em relação à higiene e tal.

Então, nota-se, pelos depoimentos, que o aluno aprendia, dentro e fora da sala de aula, questões que ajudavam na sua formação para além dos saberes meramente escolares.

A situação descrita pelo professor J. B. era semelhante à relatada pela professora L. F., quem afirmou:

Parece que, mesmo perdendo aquele tempo, você ganhava com outro aspecto, por exemplo, de já ter responsabilidade desde cedo de cuidar, de deixar limpo, né? Hoje não! Parece que encontram tudo pronto. Então, não têm uma preocupação, jogam o lixo no chão... [Antes] não destruíam, eles aprendiam o serviço doméstico. 
Por essas falas, percebemos que a experiência fora da sala de aula tinha uma função não só pedagógica, em termos de favorecer o conhecimento escolar, mas também social, adquirindo, dessa forma, importância significativa no aprendizado escolar e na formação mais ampla das crianças, como relatou a professora Y. C. (grifo nosso): “A gente vivenciava a horta escolar que a gente fazia com o aluno e dali tirava as aprendizagens, né? Como da própria roça que cada um tinha e era o meio mesmo onde estava inserida a escola; era o que a gente tinha como laboratório vivencial".

Com base nesses depoimentos, sem desconsiderar as precárias condições de trabalho à qual estavam submetidos, podemos asseverar que os professores procuravam "aproveitar", no processo de ensino-aprendizagem dos alunos, todas as situações vivenciadas do ponto de vista administrativo e organizacional. É possível observar que as atividades realizadas fora da sala de aula impulsionavam a aprendizagem da criança em um sentido mais ativo e interdisciplinar, uma vez que os discentes relacionavam o conteúdo trabalhado na escola com a realidade vivenciada fora do ambiente escolar, assim fornecia meios para desenvolver e alargar o saber, estimulando a produção de conhecimentos.

Cabe dizer que, na seleção das estratégias de ensino, há sempre que se refletir sobre os objetivos que elas cumprem e se vão ao encontro ou não da formação almejada, visto que as técnicas:

\footnotetext{
[...] não são neutras e o educador não pode usá-las sem se questionar a respeito dos valores que elas transmitem [...]. Um material didático pode ter uma aparência muito atrativa, utilizar procedimentos criativos e, ao mesmo tempo, estar a serviço de um projeto educacional muito conservador e reprodutor dos valores dominantes [...]. A pesquisa pode ser uma busca criativa ou uma perda de tempo, quando o(a) educando(a) não sabe o que e nem para que está pesquisando. Um audiovisual pode ser o meio mais eficaz para transmitir uma verdade fechada e alheia à realidade do educando(a) ou um estímulo criativo para despertar novas dimensões e conhecimentos. (ZABATIERO, 2009, p. 18).
}

Portanto, percebe-se que não era somente nas salas de aula que os estudantes aprendiam, havia diferentes situações por eles vivenciadas por meio das quais obtinham algum tipo de aprendizagem que serviria para sua vida e sua realidade. A necessidade de a escola rural pensar o trabalho pedagógico tendo presente a realidade local é um princípio que, embora ainda hoje careça de uma maior efetividade, veio a ser resguardado na LDBEN n 9.394/1996, em seu artigo 28, incisos I, II e III, conforme destacado adiante: 
I - conteúdos curriculares e metodologias apropriadas às reais necessidades e interesses dos alunos da zona rural; II - organização escolar própria, incluindo adequação do calendário escolar às fases do ciclo agrícola e às condições climáticas; III - adequação à natureza do trabalho na zona rural.

O "saber aprender" é produzido no decorrer de nossas vidas, por intermédio de relações e interações com a sociedade, com o meio em que vivemos e com o trabalho, em uma permanente articulação entre teoria e prática, na busca por resolver nossos problemas e de nosso grupo social e para entender o mundo em que vivemos. Observamos que a vida no campo é baseada nessas relações e interações e está associada a elas e que os relevantes relatos dos professores nos fazem refletir sobre o processo de aprendizagem na escola rural, que não pode perder de vista todas essas interações/conexões, sob pena de ficar destituído de sentido social para os sujeitos dos territórios rurais.

Cabe enfatizar, contudo, que o reconhecimento dos diversos espaços de aprendizagem e interações não pode eximir o poder público da responsabilidade de estruturar adequadamente as escolas rurais do campo, que anseiam por boas condições de trabalho, tanto em termos de infraestrutura quanto em termos de investimento na formação e carreira docente.

É interessante a fala da professora Y. C. ao descrever que, enquanto ela ia trabalhando atividades com alguns alunos, aqueles que já sabiam ler tomavam a leitura dos mais pequenos, possibilitando, assim, a interação social, o companheirismo e a união entre os discentes. Outra estratégia interessante evidenciada nas entrevistas foi a forma pela qual a professora C. A. desenvolvia seu trabalho pedagógico. Para trabalhar com os educandos iniciais e com os do 40 e 5ㅇ anos, ela separava a sala em dois lados e trabalhava com o livro de um lado e com o quadro de outro. Segundo ela, esse método de ensino era eficiente e fazia com que o aluno aprendesse mesmo estudando em uma sala multisseriada.

Os professores também empregavam diferentes técnicas e estratégias de ensino, desde alfabetizar pelo método global ou pelo sintético, por temas geradores ou mesmo pela pesquisa. Constatando essa questão, cabe trazer à baila o depoimento do professor J. B., que, além de docente, também foi coordenador do Projeto Logos II:

\footnotetext{
Me recordo que um coordenador de área da época falava assim: 'Olha a professora, coitada! Ela chega a orientar os alunos, ou seja, ela aplica o método da globalização, da palavração, mas, antes disso, ela já fez pelo ba-be-bi-bo-bu'. Então aquela cartilha 'Caminho Suave', aquelas cartilhas todas eram muito utilizadas, e o processo da
} 
silabação era o que era utilizado. Houve uma rejeição muito grande, mas como havia, digamos, a fiscalização e tal, eles se utilizavam dessa estratégia de ensinar pela silabação e aí orientavam os alunos. Falavam: 'Olha, se vier algum inspetor aqui, vocês vão dizer que nós fomos até a granja e que lá vocês anotaram mentalmente as palavras, o tema gerador era granja, mas vocês anotaram o que viram, vocês viram galinha, vocês viram pintinho'. E aí, na hora, digamos, de ensinar esses dígrafos e esses encontros consonantais do 'inho' do 'nh', na realidade, era pelo sistema antigo, pelo método alfabético e pela silabação.

Em eventos sobre educação e no curso de Pedagogia, muitos professores relatam a imensa dificuldade de trabalharem com classes multisseriadas, ou seja, lidarem com tantos alunos de idades e séries diferentes em uma mesma sala de aula. No entanto, com as informações dadas por esses professores entrevistados, chegamos à conclusão de que trabalhar assim é difícil, sim, mas não impossível. Pelas entrevistas realizadas, percebemos que havia várias formas de os docentes trabalharem com esses alunos de distintos níveis de aprendizagem juntos, por exemplo: fazendo leituras, tomando tabuadas, até interpretando e produzindo textos.

Hage (2006, p. 309) evidencia que os professores geralmente, numa situação dessa natureza, tendem simplesmente a seguir as indicações do livro didático, sem, contudo, "[...] atentar com clareza para as implicações curriculares resultantes dessa atitude, uma vez que esses materiais didáticos impõem a definição de um currículo deslocado da realidade e da cultura das populações do campo". Hage (2006, p. 309) identificou ainda angústias nos professores ao organizar o trabalho pedagógico em turmas multisseriadas, porque eles:

[...] assumem a visão da multissérie enquanto 'junção de várias séries ao mesmo tempo e num mesmo espaço', passando a elaborar tantos planos de ensino e estratégias de avaliação da aprendizagem diferenciadas quantas forem as séries presentes em sua turma. Como resultado, os professores se sentem ansiosos ao pretender realizar o trabalho da melhor forma possível e, ao mesmo tempo, perdidos, carecendo de apoio para organizar o tempo escolar, numa situação em que atua em várias séries concomitantemente. Eles também se sentem pressionados pelo fato de as secretarias de educação definirem encaminhamentos padronizados de horário do funcionamento das turmas, de planejamento e listagem de conteúdos, reagindo de forma a utilizar sua experiência docente acumulada e criatividade para organizar o trabalho pedagógico adotando medidas diferenciadas em face das especificidades das turmas.

Diante desse quadro, a forma com que os conteúdos são trabalhados evidencia que a prática docente compreende um conjunto de relações e procedimentos que engendra o processo de construção de conhecimento articulado com o meio em que vive. Tal ponto de vista é confirmado por Tardif (2002, p. 18-19): 
Os diversos saberes e o saber fazer dos professores estão longe de serem produzidos por eles mesmos ou de se originarem no trabalho cotidiano. Ao contrário, os saberes dos professores contêm conhecimentos e um saber fazer cuja origem social é patente. Por exemplo, alguns deles provêm da família do professor, da escola que o formou e de sua cultura pessoal; outros vêm das universidades ou das escolas normais; outros estão ligados à instituição (programas, regras, princípios pedagógicos, objetivos, finalidades, etc.); outros ainda provêm dos pares, dos cursos de reciclagem, etc. Nesse sentido, o saber profissional está, de um certo modo, na confluência de vários saberes oriundos da sociedade, da instituição escolar, dos outros atores educacionais, das universidades, etc.

Nesta pesquisa, também notamos as semelhantes dificuldades encontradas pelos professores na realização do trabalho pedagógico, quase sempre relacionadas às condições de deslocamento e acesso às escolas, tais como estradas e transporte escolar (inexistentes em alguns lugares). Essas dificuldades referiam-se também ao trabalho com turmas multisseriadas, à falta de recursos e materiais didáticos e à falta de investimento na formação dos professores, pois, à época, a maioria não tinha ensino superior nem ensino médio completo - muitos haviam estudado somente até o ensino fundamental.

Eu comecei numa escola rural pequena, não tinha diretor. Era assim: o professor lá era tudo, era professor, merendeiro, faxineiro. Esse foi o meu iniciar [...]. Tinha a dificuldade de acesso à estrada, né? Era muito difícil! Então, você tinha toda a problemática junto com a educação. Na verdade, é o contexto até hoje, claro que hoje já melhorou, mas, na realidade, aquele período era muito mais. (Professora C. A.).

[...] Professores leigos sem nenhuma formação metodológica voltada para essas escolas. Então, assim, a gente não tinha nem as discussões do que era o ensino, discussões políticas, a gente não tinha nesse momento. Então, tudo isso eu aprendi atuando [...]. No período que eu não tinha aula na escola, eu passava à tarde todinha fazendo atividade para eles. A gente não tinha recurso para fazer cópia; depois que chegou o mimeógrafo a álcool, a gente tinha o estêncil, então era tudo assim recortado de material que eu ganhava de alguém. (Professora Y. C.).

A falta de formação foi apontada pelos professores como uma das maiores dificuldades que eles encontraram, porque trabalhar com uma turma multisseriada é complicado; por isso, é que havia sempre a necessidade de buscar orientação com a SME ou então buscar cursos de aperfeiçoamento, como o Projeto Homem-Natureza ${ }^{2}$ e o Projeto Logos $\mathrm{II}^{3}$, para terminar os estudos e ter uma boa formação para trabalhar com os estudantes.

2 Segundo Machado e Gentil (2016, p. 9): “[...] o Projeto Homem-Natureza foi um projeto de formação de magistério, em nível médio, para professores leigos de zona rural, coordenado pela Seduc/MT e realizado em parceria com 15 municípios, aprovado pelo Parecer no 259/91 do CEE e Resolução no 309-A/88 do CEE".

3 Machado e Gentil (2016, p. 4) salientam que o Projeto Logos II “[...] foi um curso de magistério supletivo, modular e à distância que visava formar professores em nível de segundo grau, implementado em vários estados do Brasil".

Educação \& Formação, Fortaleza, v. 2, n. 6, p. 139-152, set./dez. 2017

DOI: http://dx.doi.org/10.25053/edufor.v2i6.2064

http://seer.uece.br/redufor 
[...] o problema das turmas multisseriadas está na ausência de uma capacitação específica dos professores envolvidos, na falta de material pedagógico adequado e, principalmente, na ausência de infraestrutura básica - material e de recursos humanos - que favoreça a atividade docente e garanta a efetividade do processo de ensino-aprendizagem. (BRASIL, 2007, p. 22).

E como havia essa precária situação, de acordo com os entrevistados, o trabalho dos professores envolvia a colaboração dos pais, dos alunos e da comunidade como um todo. Havia constantemente a colaboração dos pais e da comunidade naquele ambiente escolar, seja para ajudar a fazer a merenda dos alunos, seja para realizar até mesmo a limpeza das escolas. Em entrevista com a professora Y. C., quando perguntada sobre essa questão da participação dos pais, ela relatou:

\begin{abstract}
Eu não tive problema nenhum com a participação dos pais em nenhuma das escolas em que eu trabalhei; inclusive, na primeira escola em que eu vim dar aula, no primeiro ano na Escola do Ararão, eles tinham fogão a lenha para fazer a merenda. Na primeira reunião que eu já fiz, coloquei que a gente tinha que fazer tudo isso; uma mãe já doou um fogão que ela tinha, os pais fizeram uma cota e compraram um botijão. Então, essa participação dos pais para colaborar e organizar a escola sempre foi muito boa!
\end{abstract}

Em meio ao quadro estrutural precarizado, os professores das escolas rurais enfrentavam situações marcadas pelo improviso para realizarem o trabalho pedagógico, mas, ao mesmo tempo, contavam com a colaboração dos pais e das crianças. Apesar do empenho dos professores e da comunidade, as escolas do campo sempre foram alvo de duras críticas quanto ao fracasso do ensino por elas ministrado. Em uma entrevista concedida à Folha de São Paulo, a professora Maria Isabel Antunes Rocha (2010, s.p.) afirmou que:

As razões do fracasso foram imputadas, quase que exclusivamente, ao baixo nível da formação docente, às classes multisseriadas, à escassez de material pedagógico e à multiatividade do professor, entre outros. Trataram à escola como produtora e produto da precariedade. Não se aproximaram das condições concretas em que ela está situada.

A análise sobre o ensino nessas escolas precisa considerar um conjunto de fatores, de modo a se evitar cometer injustiça com os professores, os quais, não raro, são culpabilizados pelos "fracassos" da escola rural. 


\section{CONSIDERAÇÕES FINAIS}

As considerações que apresentamos aqui são resultados dos processos investigativos formulados para caracterizar quais eram os recursos e materiais didáticos utilizados pelos professores das escolas rurais de Tangará da Serra e identificar a forma de organização do trabalho pedagógico e as estratégias de ensino criadas por eles para realizarem seu trabalho docente nas décadas de 1980 e 1990.

As falas dos professores entrevistados deixaram evidente que as condições de atendimento à educação rural, nesse período, eram precárias, apesar de haver o acompanhamento periódico por parte da SME. Essas escolas se encontravam em comunidades rurais afastadas das sedes dos municípios, tinham uma infraestrutura inadequada, pois não tinham prédio próprio, possuíam somente uma sala de aula, onde se realizavam as atividades da escola e da comunidade, uma vez que a população não atingia o número necessário de discentes para formar uma turma; situação semelhante foi evidenciada também em outras regiões do Brasil por outros pesquisadores, a exemplo de Hage (2006). Nessas localidades de Mato Grosso, à época, constataram-se também a necessidade de focar a formação dos professores e a ausência de recursos didáticos para a realização do trabalho pedagógico.

Nesse sentido, compreendemos que a educação do campo historicamente não recebeu o apoio necessário por parte do poder público, por isso esteve sujeita a essas inconsistências que perduravam nessas escolas. De modo particular, a educação rural foi alvo de políticas compensatórias e emergenciais (MACHADO, 2009), que se configuravam como políticas de governos - findavam junto com o mandato dos governantes -, e não como políticas de Estado, sustentando-se ao longo do tempo.

Contudo, o apoio das comunidades e dos pais desses alunos fez com que essas "escolas do improviso" (FARIA FILHO, 2000 apud SOUZA; AMÂNCIO, 2006, p. 3) compartilhassem ações coletivas com o intuito de colaborar para o sucesso do ensino, para a popularização do conhecimento e também para a transformação da realidade local. Vemos, portanto, que essa colaboração foi fundamental para que o professor ou a professora não se sentisse tão só e assoberbado(a) na realização das atividades e práticas pedagógicas. Da mesma forma, cabe destacar a importância de projetos de formação de professores implementados nesse período, a 
exemplo do Logos II e do Homem-Natureza, que trouxeram elementos epistemológicos e pedagógicos que contribuíram para o processo de profissionalização dos docentes das escolas rurais no período abordado na pesquisa que fizemos.

\section{REFERÊNCIAS}

BRASIL. Campo: diferenças mudando paradigmas. Brasília, DF: Secad, 2007.

BRASIL. Lei no 4.024, de 20 de dezembro de 1961. Fixa as Diretrizes e as Bases para o Ensino de 1ㅇ e 2ㅇ graus, e dá outras providências. Diário Oficial [da] República Federativa do Brasil, Poder Executivo, Brasília, DF, 27 dez. 1961.

BRASIL. Lei no 9.394, de 20 de dezembro de 1996. Estabelece as Diretrizes e Bases da Educação Nacional. Diário Oficial [da] República Federativa do Brasil, Poder Executivo, Brasília, DF, 21 dez. 1996.

BRASIL. Ministério da Educação. Conselho Nacional de Educação. Resolução CNE/CEB no 1, de 3 de abril de 2002. Institui as Diretrizes Operacionais para a Educação Básica nas Escolas do Campo. Diário Oficial [da] República Federativa do Brasil, Poder Executivo, Brasília, DF, 9 abr. 2002.

BRASIL. Programa nacional de educação de jovens integrada com qualificação social $e$ profissional para agricultores(as) familiares. Brasília, DF: Secad, 2008.

FARIA FILHO, L. M. Os tempos e espaços escolares no processo de institucionalização da escola primária no Brasil. In: CONGRESSO BRASILEIRO DE HISTÓRIA DA EDUCAÇÃO, 6., 2006, Goiânia. Anais... Goiânia: PUC, 2006.

HAGE, S. M. Movimentos sociais do campo e afirmação do direito à educação: pautando o debate sobre as escolas multisseriadas na Amazônia paraense. Revista Brasileira de Estudos Pedagógicos, Brasília, DF, v. 87, n. 217, p. 302-312, 2006.

IBGE. Estimativa da população. Disponível em: <http://cod.ibge.gov.br/ema5>. Acesso em: 7 mar. 2017.

LÜDKE, M.; ANDRÉ, M. E. D. A. Pesquisa em educação: abordagens qualitativas. 2. ed. São Paulo: Pedagógica e Universitária, 1986.

MACHADO, I. F. Um projeto político-pedagógico para a escola do campo. Cadernos de Pesquisa: Pensamento Educacional, Paraná, v. 4, n. 8, p. 191-219, 2009.

MACHADO, I. F.; GENTIL, H. S. Formação de educadores do campo em Mato Grosso nas décadas de 1980-1990. In: ENDIPE, 18., 2016, Cuiabá. Anais... Cuiabá: Endipe, 2016.

Educação \& Formação, Fortaleza, v. 2, n. 6, p. 139-152, set./dez. 2017

DOI: http://dx.doi.org/10.25053/edufor.v2i6.2064

http://seer.uece.br/redufor 
PINHEIRO, M. S. D. A concepção de educação do campo no cenário das políticas públicas da sociedade brasileira. In: CONGRESSO LUSO-BRASILEIRO DE POLÍTICA E ADMINISTRAÇÃO DA EDUCAÇÃO, 5., 2007, Porto Alegre. Anais... Porto Alegre: UFRGS, 2007. p. 1-20.

RIBEIRO, M. Política educacional para populações camponesas: da aparência à essência. Revista Brasileira de Educação, Rio de Janeiro, v. 18 n. 54, p. 669-691, 2013.

ROCHA, M. I. A. Em discussão, a precariedade da educação rural Brasil. Entrevista de Maria Isabel Antunes Rocha para a Folha de São Paulo. Folha de São Paulo, São Paulo, Coditiano, 13 jun. 2010. Disponível em: <http://www1.folha.uol.com.br/fsp/cotidian/ff1306201016.htm>. Acesso em: 10 set. 2014.

SOUZA, M. A. Educação do campo: propostas e práticas pedagógicas do MST. Petrópolis: Vozes, 2006.

SOUZA, T. F. M.; AMÂNCIO, L. N. B. Escolas rurais e alfabetização em Diamantino-MT: aspectos de uma trajetória nas décadas de 1930 a 1940. In: CONGRESSO BRASILEIRO DE HISTÓRIA DA EDUCAÇÃO, 4., 2006, Goiânia. Anais... Goiânia: UCG, 2006.

TARDIF, M. Saberes docentes e formação profissional. 16. ed. Petrópolis: Vozes, 2002.

ZABATIERO, J. Novos caminhos para a educação cristã. São Paulo: Hagnos, 2009.

Recebido em 16 de setembro de 2016. Aceito em 17 de agosto de 2017. 